\title{
INTEGRATION OF TRIZ INTO QUALITY FUNCTION DEPLOYMENT
}

\author{
Philipp Tursch, Christine Goldmann, Ralf Woll \\ Chair of Quality Management, Brandenburg University of Technology Cottbus-Senftenberg, Germany \\ Corresponding author: \\ Philipp Tursch \\ Brandenburg University of Technology Cottbus-Senftenberg \\ Chair of Quality Management \\ Siemens-Halske-Ring 14, 03046 Cottbus, Germany \\ phone: (+49) 355693947 \\ e-mail: philipp.tursch@b-tu.de
}

Received: 2 April 2015

Accepted: 5 May 2015

\begin{abstract}
Purpose: The objective of successful companies is the integration of customer requirements in the development process of a new product. Therefore, the Quality Function Deployment method has proven useful several times. The customer requirements often contain contradictions, which are mostly solved by compromises. The aim should be to integrate all customers' demands and wishes into future products.

Methodology: The theory of inventive problem solving can be applied to eliminate compromises in the product development. The method's different tools enable a goal-oriented and systematic conflict resolution and may help to uncover trends. This paper displays an approach where individual tools of TRIZ are integrated into the Quality Function Deployment. Results: The result of this work is the presentation of the resulting benefits from combining the two methods. For this reason, individual tools of TRIZ are used in different points of the QFD process. The paper shows examples of starting points.

Value of paper: In the context of this paper, the benefits from the interaction of QFD and TRIZ are presented. These are particularly evident in the initial phase of project implementation. In this phase the goal of the QFD process is to succeed in translating the voice of the customer for the company and then integrating it into the product development.
\end{abstract}

KEYWORDS

innovative product development, integration, TRIZ, QFD.

\section{Introduction}

Today's development of technologies is progressing in rapid pace and in the future innovations will be increasingly important. A company that wants to survive in the market has to create innovative products and needs market-driven planning and design. Only in this way customers can be satisfied and high sales and profits are available in new and existing markets [1]. In order to achieve a company's future success, high standards must be ensured which are consistently oriented toward customer value [2].

The aim should be to enhance the user experience in coordination with the customer requirements and involve these into the product development or processes. Quality Function Deployment has proven successful in accomplishing this aim. Nevertheless, with QFD usually contradictions arise that need to be solved. A very goal-oriented method for solving contradictions is TRIZ - theory of inventive problem solving. TRIZ offers numerous tools that enable a targeted and especially systematic problem solving.

\section{Presentation of the basic methods QFD and TRIZ}

\section{Presentation of Quality Function Deployment}

A completely systematic approach and overarching planning method for the fulfillment of customer demands is the Quality Function Deployment, hereinafter simply called QFD [3]. The customer wishes, needs and notions are identified in the QFD method- 
ology and serve as the basis for the entire product development [4].

The QFD process begins with the determination of the customer requirements and ends with the realization of the processes necessary for the production [4]. The QFD methodology is generally understood as a work style and a working philosophy with the aim to completely satisfy the customers. The focus lies on two key issues: WHAT does the customer want and HOW can it be achieved? For this purpose, all employees' knowledge and skills are involved in the strategies and actions to achieve this aim, therewith avoiding an aberration [1].

QFD consequently pursues the ultimate objective: "Success for the customers, the employees and the entrepreneur" [5].

This is supplemented by the following sub-goals:

- Customers' enthusiasm,

- Intensification of teamwork,

- Clear, coordinated and measurable goals,

- Reduce losses in the value chain,

- Fewer and shorter development steps,

- Systematic documentation,

- Incorporation of expert knowledge and

- (Permanent) quality development and improvement [5].

The initially increased effort with which the method needs to be introduced to the company can be considered disadvantageous [6].

With QFD, it is possible to achieve a high level of customer satisfaction since customer demands are included in the development process from the beginning. Innovative solutions are, however, not increased by the use of this method but only in this way it is possible to develop a competitive advantage and thus to secure high market shares.

Supplementing the QFD method with other quality-enhancing ways of working, such as TRIZ, it is possible to achieve synergies and to arrive at innovative customer-exciting product developments.

\section{Presentation of the theory of inventive problem solving}

"Having a good idea first is crucial for the success of a company" [7]. A systematic and analytical work is required to fulfil high customer demands, the intensified competition and, not least, the increasing cost pressure [8]. At this point it is useful to use the "Theory of Inventive Problem Solving" to systematically find ideas and to reach innovative concepts [9]. This theory resulted from the work of Genrich Altshuller in the $1950 \mathrm{~s}$.
Altshuller had the opinion that the random development of ideas can most widely be replaced by a structured problem-solving process [5]. To prove his theory, he and his staff analyzed and compared over 2.5 million patents, of which 40,000 revealed a high level of innovation. They came to the conclusion that:

- Similar problems and solutions are repeated in all scientific disciplines,

- The evolution of technical systems always follows similar patterns and,

- Real innovations use scientific effects outside of their own field of activity [10].

Based on these findings, Altshuller developed the core elements of TRIZ and perfected them over a period of almost 42 years with the goal of creating a science of creativity [7].

TRIZ stands not only for a single method, it has several operating principles, strategies, thoughts and notes, which offer a unique opportunity to increase the innovativeness and to radically improve processes or products [8]. Altshuller tried to define TRIZ as follows: "TRIZ is a methodology that provides developers with an experience and knowledge concentrate including a User's Guide to systematic innovation. The system is particularly suited to provoke creative innovations" [5].

Resolving contradictions or conflicts without compromise is the central principle of TRIZ philosophy. In contrast to other creativity techniques, this method separates unsuccessful approaches, works purposefully and systematically while overcoming the psychological inertia [10].

\section{The four pillars of TRIZ}

TRIZ includes a toolbox of different approaches to creative problem solving and idea generation which is structured into four classes called "The Four Pillars of TRIZ": systematics, knowledge, analogy and vision. These can be used individually or in combination to solve the problem [11].

Systematics:

The tools of the first pillar include various methods serving the structured and systematic analysis of the problem and at the same time overcoming thinking barriers [12].

Knowledge:

The knowledge-based tools from the second pillar equip the users with the accumulated knowledge of mechanics, physics, thermodynamics and chemistry. By applying these tools, the user's own horizon of knowledge is greatly enhanced by acquainted knowledge, the databases and research. Additionally, the process of problem solving is supported [12]. 


\section{Analogy:}

In the analogy section of the third pillar, tools are offered that deal with the description and resolution of conflicts and contradictions. The specific problem is transformed to an abstract level where fixed solution approaches are available that provide a basis for finding your own special solution. The goal is not to make compromises but to always remove technical and physical contradictions. This approach offers an access to the problem which is independent of industry and area of expertise [9].

Vision:

The tools of the fourth pillar are used to determine the exact location of the own product. Therewith, accurate predictions about the future development can be made [9].

The particular TRIZ tools are used for analysis and the subsequent resolution of conflicts and contradictions without having to rely on compromise solutions [10]. A specific procedure in the order of the application of the tools is not necessary but the approach always needs to be adapted to the individual problem or the company. TRIZ provides tools that are aligned either more analytic or more knowledgebased [7].

\section{Applications of TRIZ}

Even since Altshuller's development of the theory of inventive problem solving in the late 1940s, nothing has changed the general solution principles [13]. The aim of the TRIZ methodology is to quickly lead to innovative concepts, thereby becoming more effective as well as efficient in the development process and to be able to react more quickly to market developments than the competitors [14]. In contrast to other methods of creativity, with TRIZ contradictions are not circumvented with compromises but are rather resolved on the basis of a technical and scientific patent analysis [10]. The limits of TRIZ correlate with the boundaries of the findings of natural sciences as this form the basis of TRIZ [15].

TRIZ is a very time-consuming method and can only be used effectively by experienced employees. It is recommended to learn the terms of TRIZ like a foreign language and to practice it. This is the only way to achieve an effective use [16]. Additionally, a high degree of the faculty of abstraction is necessary for a successful application of the theory of inventive problem solving [17]. Because some tools of TRIZ have high complexity, it can be helpful to integrate TRIZ experts in the project team for the first implementation in the company [18].
In recent years, TRIZ has gained importance and is increasingly used in companies for general problem solving [9]. Furthermore, the application of TRIZ should be promoted within a company because it helps to come up with innovative solutions for problems, to develop a product strategy, to prevent errors in the development and to stimulate creativity [14]. Through the application of TRIZ tools, it is possible to develop patentable solutions and thus to counteract the increasing competitive pressure through innovation [14]. TRIZ does not present complete solution concepts but rather supplies the users with basic solutions which still need to be developed for implementation [14].

The areas of application of TRIZ are not limited to the development of new products. The procedure can be implemented into the entire functional set-up of a company [10]. Nevertheless, without the software support TRIZ is rather impractical and very time consuming for finding ideas. Meanwhile, a number of providers offer computer-assisted processes based on TRIZ [11]. For the successful use of the software, sufficient methodological background knowledge is required [17].

Although problems with TRIZ have been resolved, this does not guarantee that the solution concepts will be accepted in the environment and will be successful [17]. Only the successful implementation of customer requests and requirements leads to a high degree of acceptance by the customer. This can be achieved by leveraging the synergy effects from the combination of the methods TRIZ and QFD [19].

The designated target of the QFD method is to translate customer requirements into technical requirements and therewith create a cause-effect chain. From this process, conflicts arise that can be solved innovatively using the TRIZ tools [8].

\section{Exemplary Implementation of TRIZ in QFD}

The benefit from the combination of both methods can be seen in the resolution of the resulting HoQ contradictions. These serve as a basis for a direct contradiction analysis within the framework of TRIZ. In particular, the TRIZ tools' contradiction table with 40 innovative principles and the four separation principles can be effectively used at this point to handle the contradictions in a very comprehensive manner and provide innovative solutions.

The tools of TRIZ method also offer a wide variety of applications in QFD, as shown in Fig. 1. 


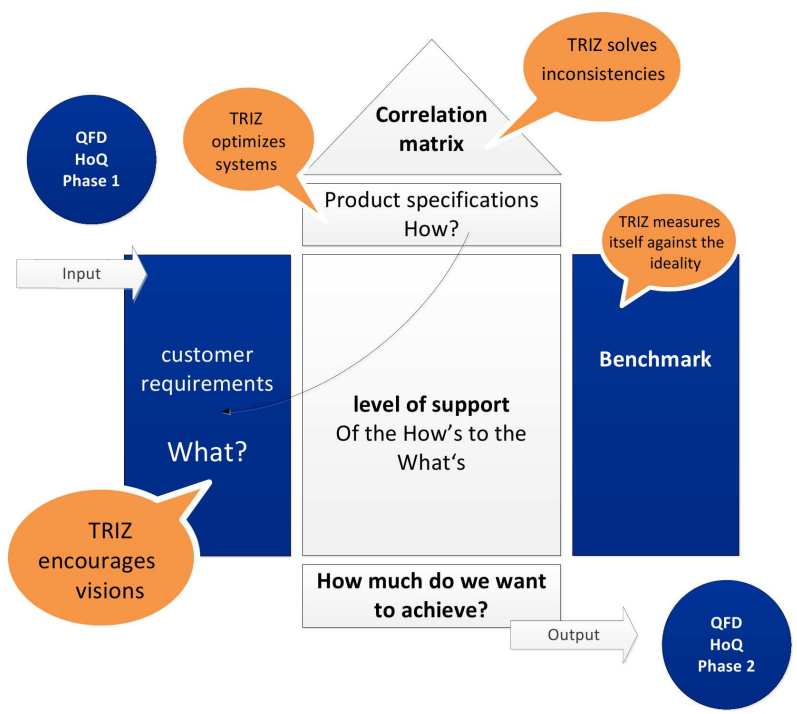

Fig. 1. Synergy effects of QFD and TRIZ [12].

The following tools can be advantageously used in the QFD process:

- As part of the innovation check list and resource analysis, all necessary information about a problem and its causes is collated and structured.

- The formulation and subsequent orientation on ideality can be used to extend the limited horizon of thought, and in this way to innovate and differentiate the company from its competitors.

- Technical and Physical Contradictions form the juxtaposition of customer requirements which are resolved using TRIZ. This also promotes new ideas.

- When translating customer requirements (WHAT) into product features (HOW), tools of TRIZ evolution laws and S-curve can be used. In this way, possible trends and technology developments can be detected early on and the desired excitement factors are encouraged.

- The substance-field-analysis can help to translate the customer requirements into technical product characteristics [10].

- The anticipatory fault detection lets systems fail intentionally, thus covers early possible sources of error and seeks countermeasures.

The theory of TRIZ was developed by Altshuller in 1946 and yet the knowledge and experiences are still limited in application, especially in connection with the QFD process. The methods of Altshuller are constantly extended by new knowledge and new ways of working for development to promote innovation.

The use of Altshuller's opposition formulation in form of 39 technical parameters is without sufficient technical and physical background knowledge quite difficult. Therefore, working with the 40 innovation principles is recommended in order to encourage creativity and to achieve leading solution ideas.

The application of TRIZ in QFD has proven to be very versatile and just as extensive. For this reason, an integration of all TRIZ tools has not been possible in this work. Therefore, the focus here was placed on solving contradictions from the HoQ, as these are essential to solve without having to make compromises.

In the TRIZ methodology, two types of contradictions are distinguished. These are listed in the following figure:

The mark of a technical contradiction lies in the simultaneous improvement $(\mathrm{A} \uparrow$ ) and degradation $(\mathrm{B} \downarrow)$ of system parameters with respect to the system performance $(\mathrm{C}=\mathrm{f}(\mathrm{A}, \mathrm{B}))$ [14].

The physical contradiction, however, calls for a certain property $(\mathrm{C}+)$ simultaneously with its opposite property $(\mathrm{C}-)$ [14].

If this definition is being followed, during the implementation of QFD technical contradictions in the mutual dependence of two quality characteristics may occur among each other. Physical contradictions of a quality characteristic emerge when the customer perspective points out different optimization directions at the same time have. In the following, the technical contradictions are considered exemplary.

The correlations among the technical characteristics (HOW's) and the associated target values and the optimization direction are shown in the roof of the QFD matrix. As outlined in the following figure, contradictions and conflicts can be read directly. Negative correlations indicate the technical-physical border areas in the development and provide guidance regarding necessary changes or the need for completely different solutions [12]. Traditionally, at this point in the QFD methodologies solutions in the form of compromises were sought after. The aim is to innovatively solve the compromises with the help of TRIZ.

At this stage, the conflict table with Altshuller's 39 technical parameters and 40 innovative principles can be effectively used to find solutions. Thus, a direct connection of QFD to TRIZ is provided.

The procedure for finding solutions with TRIZ is the following: A specific problem is abstracted into a typical problem. With the help of the basis of the 39 technical parameters, the inconsistencies would be formulated. By the matrix of contradictions is it possible to find a typical solution. This typical solution would with the help of the 40 innovative principles concretized into the specific solution [9].

From the roof of the HoQ, characteristics with the greatest conflicts among themselves are retrieved. 
Since they have the greatest negative values, the conflict needs solving.

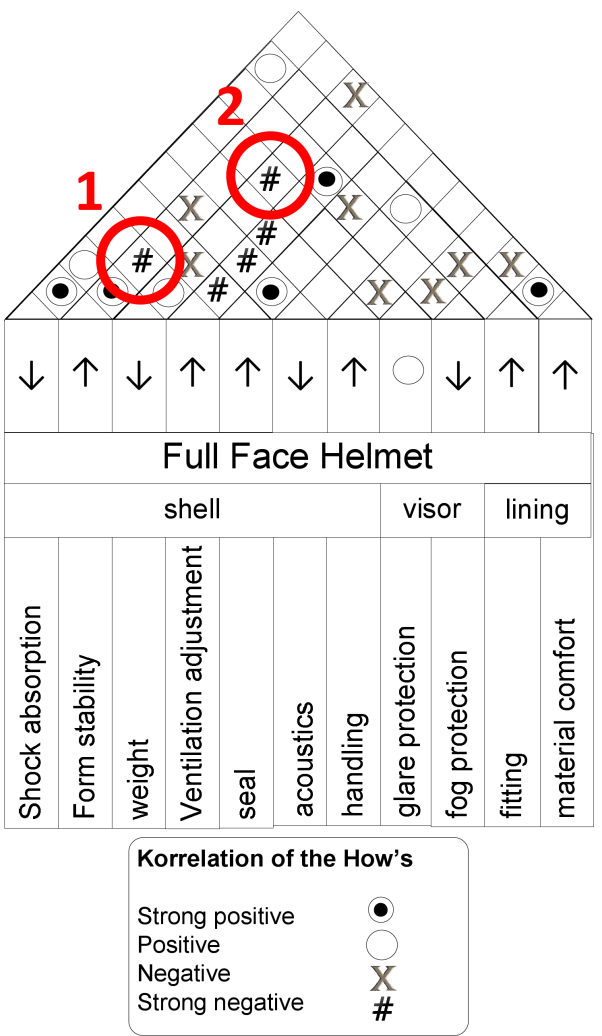

Fig. 2. Extract the roof matrix of the first HoQ.

Using the example of a full-face helmet five strong negative correlations occur. For this reason, two contradictions and have four different technical parameters, are exemplarily edited with TRIZ in the following.

Example (1): The increase of the material strength of the full-face helmet $(\mathrm{A} \uparrow$ ) leads to a deterioration of the ventilation ( $\mathrm{B} \downarrow$ ) which therefore results in a strong negative correlation in the matrix.

Specific problem (1): The form stability of the full-face helmet shall be increased but must not lead to a deterioration of ventilation.

Now it is time to try to abstract this specific problem so that it may be presented as a contradiction in the 39 technical parameters.

The following general opposition could describe the initial situation quite accurate:

Typical problem (1): The improvement of the strength (matrix of contradictions (moc 14) leads to a decrease of the possible changes of the mold (moc 12).

Product characteristic A: Increase material strength $\rightarrow$ technical parameter: strength (moc 14).
Product characteristic B: Improve ventilation regulation $\rightarrow$ technical parameter: mold (moc 12 ).

Analysis of a contradiction: The technical contradictions are compared in the contradiction matrix. This reads as follows: Improving parameter A $(\mathrm{A} \uparrow)$ results in an undesirable change of parameter $\mathrm{B}(\mathrm{B} \downarrow)$.

Typical solution (1): At the intersection of the two parameters the following innovative solution principles for the contradiction are available:

10 Preliminary action $\rightarrow$ the required effect is to be obtained in advance (in whole or in part),

30 Flexible shells and thin films $\rightarrow$ Instead of the usual rigid structure films, flexible shells and thin films are to be used,

35 Parameter changes $\rightarrow$ Change the physical state of an object: solid, liquid, gaseous, but also quasi-liquid or change properties such as concentration, density, elasticity, temperature,

40 Composite materials $\rightarrow$ convert the same materials to composite materials [14].

These typical solutions are given by the matrix of contradictions. Now it is time to assign and apply these typical solutions to the specific problem. The aim is to develop a solution which combines the different requirements of the system in a manner that both may co-exist.

Specific solution (1): Principle 10 (Preliminary action) may advise to reconsider the principle of air holes. Instead of complete penetrating holes a kind of "grid" can be placed in front of the openings which is directly connected to the helmet shell and thus provides an additional stabilization.

Principle 35 (Parameter changes) leads to the idea to use a material other than the usual thermoplastic granules for the preparation of the shell. Carbon fibers may be incorporated to increase the strength.

This solution has already been successfully used by some manufacturers of motorcycle helmets. However, the processing of the material is considerably more expensive.

Another example follows to internalize the process of solving another technical contradiction.

Example (2): The integration of a glare protection in the helmet $(\mathrm{A} \uparrow)$ leads to an increase in the helmet's weight $(\mathrm{B} \downarrow)$. This is why the, HoQ matrix at this point shows a strong negative correlation.

Specific problem (2): A glare protection shall be integrated but must not lead to an increase in the weight of the helmet.

Typical problem (2): By augmenting the reliability (moc 27), the mass of the movable object (moc 1 ) is increased. 
Product characteristic A: Integrate glare protection $\rightarrow$ technical parameter: reliability (moc 27 )

Product characteristic B: Reduce weight $\rightarrow$ technical parameters: mass of the movable object (moc 1)

Typical solution (2): The following innovative principles for the solution of this contradiction are available:

3 Local quality $\rightarrow$ Different parts of the object are supposed to perform different functions,

8 Anti-weight $\rightarrow$ The mass of the object is to be brought together by coupling with another object that has corresponding load-carrying capacity [13].

For principle 10 and 40 see above.

Specific solution (2): For this example, principle 3-local quality may lead to a solution when visor is developed which automatically darkens in strong sunlight, similar to a pair of glasses. In this way, a normal clear visor turns through UV radiation in a sunscreen and an extra visor (to switch or integrated) is no longer necessary. The visor should adjust its tint depending on the brightness level as well as brighten and go back to its original state at increasing darkness. At this point, the therefore required time needs to be tested to ensure good visibility even with shortterm fades or for example a tunnel ride and to effectively protect the eyes from sun rays. Additionally, the impact of temperature on the effect of shading must be examined.

The principle 10-preliminary action could be implemented by integrating a thin film which has already been integrated into the helmet. This can be rolled over the sun visor and fastened on the other side. When the function of sun protection is no longer required the film can be automatically rolled up like a window shade. Research has shown that there are already ideas building upon this recommendation. A helmet visor was developed which darkens and can be clear again at the touch of a button.

\section{Conclusion}

This work identified advantages from the interaction of QFD and TRIZ. They are particularly evident in the initial phase of project implementation. In this phase of the QFD process the goal is to succeed in translating and integrating the voice of the customer for and in the company. TRIZ can support this process through revealing contradictory requirements early on and, in contrast to the usual compromise in QFD, solve them.

With the help of the examples it became clear that it is advantageous to apply the TRIZ tools to the product development. An interdisciplinary QFD-
TRIZ process can eliminate thinking barriers and extend the knowledge horizon. Through the use of technical terms in some TRIZ tools, such as the innovative principles, the incorporation of experts is recommended in some places of problem solving. Similarly, the use of the appropriate software for TRIZ is advisable for the application of the matrix to shorten the process.

The individual TRIZ tools as well as their goals and capabilities need to be accurately known, otherwise their use is not recommended. The immense amount of time which is necessary for the incorporation into TRIZ can be compensated by the use of a qualified and trained TRIZ moderator. This is also advisable, individually or in conduct, in conjunction with QFD during the use of TRIZ. Without a moderator is otherwise possible to quickly lose track of the variety of possible applications.

A successful combination of the two methods ensures the prerequisites for a successful product: customer orientation and innovation.

A combination of TRIZ in QFD can generate enormous potential for innovation and is highly recommended.

\section{References}

[1] Deutsche Gesellschaft für Qualität e.V., Frankfurt, QFD - Quality Function Deployment, Berlin, Wien, Zürich: Beuth Verlag GmbH, 2001.

[2] Malorny C., TQM umsetzen: Weltklasse neu definieren, Leistungsoffensive einleiten, business excellence erreichen, 2nd ed. Stuttgart: SchäfferPoeschel, 1999.

[3] Kamiske G.F., Pocket Power: Prozessoptimierung mit Quality Engineering, München, Wien: Carl Hanser Verlag, 2004.

[4] Spath D., Linder C., Seidenstricker S., Technologiemanagement: Grundlagen, Konzepte, Methoden, Stuttgart: Fraunhofer Verlag, 2011.

[5] Klein B., QFD - Quality Function DeploymentKonzept, Renningen: Expert Verlag, 2012.

[6] King B., Doppelt so schnell wie die Konkurrenz, 2nd ed. Schweiz: gfmt Verlag, 1994.

[7] Terninko J., TRIZ - Der Weg zum konkurrenzlosen Erfolgsprodukt, Landsberg/Lech: mi, Verl. Moderne Industrie, 1998.

[8] Koltze K., Souchkov V., Systematische Innovation. TRIZ-Anwendung in der Produkt- und Prozessentwicklung, München: Hanser, 2011. 
[9] Gimpel B., Herb R., Herb T., Ideen finden, Produkte entwickeln mit TRIZ, München: Hanser Verlag, 2000 .

[10] Teufelsdorfer H., Conrad A., Kreatives Entwickeln und innovatives Problemlösen mit TRIZ/ TIPS, München: Siemens AG Verlag, 1998.

[11] Engeln W., Methoden der Produktentwicklung - Skripten Automatisierungstechnik, 2nd ed. München: Oldenbourg Industrieverlag, 2011.

[12] Saatweber J., Kundenorientierung durch Quality Function Deployment, 3rd ed Düsseldorf: Symposion Publishing GmbH, 2011.

[13] Herb R., TRIZ - der systematische Weg zur Innovation, Landsberg/Lech: mi, Verlag Moderne Industrie, 2000.

[14] Klein B., TRIZ/TIPS. Methodik des erfind- erischen Problemlösens, München: Oldenbourg Wissenschaftsverlag, 2007.

[15] Orloff M.A., Grundlagen der klassischen TRIZ, 3rd ed. Heidelberg: Springer-Verlag, 2006.

[16] Gundlach C., Innovation mit TRIZ - Konzepte, Werkzeuge, Praxisanwendungen, Düsseldorf: Symposion Publishing, 2006.

[17] Schweizer P., Systematisch Lösungen realisieren: Innovationsprojekte leiten und Produkte entwickeln, Zürich: vdf, Hochschul.-Verlag, 2001.

[18] Schmitt R., Pfeifer T., Qualitätsmanagement: Strategien - Methoden - Techniken, 4th ed. München, Wien: Carl Hanser Verlag, 2010.

[19] Pfeifer T., Qualitätsmanagement - Strategien, Methoden, Techniken, 3rd ed. München: Carl Hanser Verlag, 2001. 